УДК 621.396

Дмитро Георгійович Шевченко (кандидат військових наук)

Національний університет оборони Украӥни імені Івана Черняховського, Київ, Украӥна

\title{
МЕТОДИКА ОЦІНЮВАННЯ ЕФЕКТИВНОСТІ ФУНКЦІОНУВАННЯ ЛІНІї ЗВ’ЯзКУ
}

В статті розглянуте актуальне питання удосконалення науково-методичного апарату оцінювання ефективності функціонування лінії зв'язку. Проаналізовані останні дослідження і публікації з цъього питання. Проведений аналіз свідчить про те, щзо иүі методики не забезпечують достатній рівень точності й об'єктивності оцінки у зв'язку з неврахуванням досвіду застосування циифрових ліній зв'язку в операціях $і$ деяких чинників, які суттєво впливають на ефективність функціонування циифрових ліній зв'язку у циих умовах.

В статті розглядається методичний підхід для вирішення прикладної задачі, який оснований на застосуванні методу векторної оцінки показника ефективності. Пропонується інтегральний показник ефективності та критерій оцінювання ефективності функціонування иифррової лінії зв'язку для розв'язання поставленої задачі. Наведені співвідношення для оцінювання зовнішніх та внутрішніх факторів та їх вплив на ефективність функціонування лінії зв'язку.

Запропонована методика дає можливість отримати більи об'єктивну та адекватну оцінку ефективності функиіонування ичифрової лінії зв'язку. Застосування даного методу векторної оцінки ефективності позбавляє необхідності вирімення проблемного питання, яке полягає у нормуванні компонент критерію оцінки, приведення до єдиних розмірності та масштабу, їх ранжуванні або призначенні вагових коефічієнтів, а також згортки окремих компонент, щзо дає можливість застосування описаного у статті методу для задач оцінювання ефективності ичифрових ліній та мереж зв'язку.

Ключові слова: система зв'язку, циифрові лінії зв'язку, ефективність, якість.

\section{Ветуп}

Постановка проблеми. Сучасні військові операції [1] різко ускладнили роботу з планування зв'язку і управлінню силами і засобами зв'язку в ході підготовки та ведення бойових дій. Істотно зросла небезпека та вага прорахунків і помилок у прийнятих рішеннях, значно збільшилася кількість питань організації зв'язку, що вимагають кількісних обгрунтувань. Тому передбачення результатів функціонування спланованої інформаційно-телекомунікаційної системи $\epsilon$ обов'язковою вимогою для обгрунтування прийнятих рішень на організацію зв'язку. Досвід проведення операцій свідчить про необхідність розвитку методів та засобів управління системою 3в'язку [2, 3], а також удосконаленні методики оцінювання ефективності функціонування іiі елементів - ліній зв'язку.

Аналіз останніх досліджень і публікацій.

Питанню дослідження ефективності функціонування системи зв'язку присвячено багато робіт [4-8] Аналіз можливості їх використання для оцінки ефективності функціонування ліній зв'язку свідчить про те, що ці методики, на жаль, не можуть забезпечити достатній рівень точності й об'єктивності оцінки у зв'язку 3 неврахуванням досвіду застосування ліній зв'язку під час проведення операцій і деяких чинників, які суттєво впливають на ефективність функціонування ліній зв'язку у цих умовах, а саме:

науково-методичний апарат пристосований лише до оцінювання окремих показників ефективності функціонування ліній зв'язку та не забезпечує достатній рівень точності й об'єктивності комплексного оцінювання;

евристичний характер відомих методів вибору характеристик та параметрів ліній зв'язку.

Ефективність функціонування цифрових ліній зв'язку залежить від багатьох умов і факторів, які носять імовірнісний характер та мають різну природу походження. Це в свою чергу викликає необхідність вирішення проблемного питання, яке полягає у нормуванні компонент критерію оцінки, приведення до єдиних розмірності та масштабу, їх ранжуванні або призначенні вагових коефіцієнтів, а також згортки окремих компонент [9-11].

Отже, метою статті $є$ застосування методу векторної оцінки для усунення вищезазначеного проблемного питання. 


\section{Виклад основного матеріалу дослідження}

Ефективність лінії зв'язку - це її властивість, яка характеризує ступінь відповідності лінії для вирішення поставлених перед нею задач. Кількісну міру даної відповідності доцільно $[12,13]$ визначати через показник ефективності $P_{\text {в }}$, a порівняльну оцінку проводити за критерієм ефективності

$$
\mathrm{I}_{\mathrm{e}}: \mathrm{P}_{\mathrm{B}} \geq \mathrm{P}_{\mathrm{B}}^{\text {потр }},
$$

де: $\mathrm{P}_{\mathrm{B}}^{\text {потр }}$ - потрібне значення показника (рівня) ефективності лінії, який визначає ступінь досягнення поставленої перед лінією зв'язку мети. Для комплексного дослідження ефективності лінії зв'язку показник ефективності $\mathrm{P}_{\mathrm{B}}=\mathrm{f}(\overrightarrow{\mathrm{X}}, \overrightarrow{\mathrm{Y}})$, який пов'язуе значення показників якості функціонування $\overrightarrow{\mathrm{X}}=\left\{\overline{\mathrm{x}}_{\mathrm{i}}\right\}$, де $\mathrm{i}=1 . . \mathrm{n}, 3$ вимогами $\overrightarrow{\mathrm{Y}}=\left\{\overline{\mathrm{y}}_{\mathrm{i}}\right\}$, де $\mathrm{i}=1 \ldots \mathrm{n}$ та їх значеннями, повинен відображати як всі можливі ефекти (результати функціонування) лінії, так i необхідні для ї досягнення витрати ресурсів, що приводить до понять “функціональної” і “економічної” ефективності. Під функціональною ефективністю лінії зв'язку розуміють ступінь відповідності ефекту (достовірності i надійності зв'язку, пропускної спроможності, рівня завадозахищеності, своєчасності, мобільності, скритності і т.ін. $[14,15])$ відповідно до вимог, які до нього висуваються, а під економічною ефективністю - ступінь відповідності витрат на розробку та експлуатацію лінії зв'язку. Оскільки вартісне вираження витрат на всіх етапах створення та експлуатації лінії зв'язку важко формалізується (у зв'язку із відсутністю деяких даних), то в подальшому під витратами будемо розуміти витрати просторового, частотного, енергетичного та часового ресурсів, які необхідні для забезпечення процесу функціонування лінії, а ступінь їх відповідності вимогам (економічну ефективність) будемо оцінювати на основі критеріїв якості $\mathrm{P}_{\mathrm{B}}$ за показниками витрат $\overrightarrow{\mathrm{X}}$ та вимог до них $\vec{Y}$. До основних показників якості, які характеризують функціональну ефективність (ефект) $\overrightarrow{\mathrm{X}}_{\text {еф }}$ лінії, зазвичай відносять:

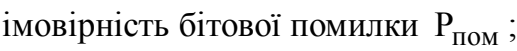

пропускна спроможність лінії $\mathrm{C}$;

коефіцієнт завадозахищеності $\mathrm{k}_{33}=\frac{\left(\mathrm{P}_{\mathrm{c}} / \mathrm{P}_{3}\right)_{\text {вих }}}{\left(\mathrm{P}_{\mathrm{c}} / \mathrm{P}_{3}\right)_{\mathrm{BX}}}$, який визначається відношенням потужності сигналу до потужності завади на виході пристрою завадозахисту до аналогічного відношення на вході;

час доставки повідомлень різної категорії терміновості $t_{s}, s=1 \ldots S$;

час розгортання станції і лінії зв'язку $t_{\mathrm{p}}$;

коефіцієнт готовності лінії (станції) зв'язку $k_{\Gamma}$;

коефіцієнт використання ресурсу $k_{\text {вр }}$.

Деякі 3 перелічених показників якості функціонування можуть одночасно виступати і як показники витрат (наприклад, $\mathrm{C}, \mathrm{t}_{\mathrm{p}}$ i т.ін.).

Оскільки умови функціонування лінії зв'язку визначаються цілим рядом випадкових факторів (випадково змінюються параметри середовища поширення, типів сигналів та завад $(\vec{A})$, а також випадковий характер вогневого ураження $(\vec{B})$, то вектори перелічених показників якості і вимог до них в загальному випадку також є випадковими:

$$
\vec{X}=\vec{X}(\vec{A}, \vec{B}) ; \vec{Y}=\vec{Y}(\vec{B}),
$$

а оцінка ефективності лінї зв'язку повинна бути ймовірнісною, тобто показник ефективності

$$
\mathrm{P}_{\mathrm{B}}=\mathrm{P}\left(\overrightarrow{\mathrm{X}}_{>}^{<} \overrightarrow{\mathrm{Y}}\right),
$$

буде представляти собою імовірність виконання завдань, які поставлені перед лінією зв'язку. При цьому етапи оцінки ефективності повинні включати визначення інтегрального закону розподілення вектора $\vec{X}$ :

$$
\Phi_{\overrightarrow{\mathrm{X}}}(\tilde{\overrightarrow{\mathrm{X}}})=\mathrm{P}(\overrightarrow{\mathrm{X}} \leq \overrightarrow{\overrightarrow{\mathrm{X}}})=\mathrm{P}\left(\prod_{\mathrm{i}=1}^{\mathrm{n}}\left(\mathrm{x}_{\mathrm{i}} \geq \widetilde{\mathrm{x}}_{\mathrm{i}}\right)\right),
$$

де знак “ $\square \square \square$ " - деяке значення випадкового процесу, а також інтегрального закону розподілення випадкового вектору

$$
\mathrm{F}_{\overrightarrow{\mathrm{Y}}}(\overrightarrow{\mathrm{Y}})=\mathrm{P}(\overrightarrow{\mathrm{Y}}<\tilde{\overrightarrow{\mathrm{Y}}})=\mathrm{P}\left(\prod_{\mathrm{i}=1}^{\mathrm{n}}\left(\mathrm{y}_{\mathrm{i}}<\widetilde{\mathrm{y}}_{\mathrm{i}}\right)\right) .
$$

Отже, у відповідності до (3) показник ефективності лінії зв’ язку

$$
\mathrm{P}_{\mathrm{B}}=\mathrm{P}\left(\overrightarrow{\mathrm{X}}_{>}^{<} \overrightarrow{\mathrm{Y}}\right)=\int_{-\infty}^{\infty} \ldots \int_{-\infty}^{\infty} \Phi_{\overrightarrow{\mathrm{X}}}\left(\stackrel{\overrightarrow{\mathrm{Y}}}{)} \mathrm{dF}_{\overrightarrow{\mathrm{Y}}} .\right.
$$

Якщо ввести позначення

$$
\omega^{(\mathrm{n})}=\mathrm{F}_{\overrightarrow{\mathrm{X}}}(\overrightarrow{\mathrm{Y}}),
$$

то отримаємо

$$
\mathrm{P}_{\mathrm{B}}=\int_{0}^{1} \omega \mathrm{dF} \mathrm{F}_{\omega}(\mathrm{n})(\omega)=\bar{\omega}^{(\mathrm{n})},
$$

де: $\omega$ - поточне значення умовної ймовірності виконання поставлених перед лінією зв'язку задач; $\mathrm{F}_{\omega}(\mathrm{n})(\omega) \quad-$ функція розподілу даної ймовірності; 
$\bar{\omega}^{(\mathrm{n})}$ - математичне сподівання (середнє) даної ймовірності.

При небагатократному (одноразовому) застосуванні лінії зв'язку відхилення від середнього значення $\bar{\omega}^{(\mathrm{n})}$ для ліній зв'язку можуть бути суттєвими, тому найкращі результати в цих умовах дає показник ефективності у вигляді гарантованої ймовірності виконання задачі:

$$
\omega^{(\Gamma)}(\gamma)=\mathrm{F}_{\omega}^{-1}(\mathrm{n})(1-\gamma),
$$

де: $\mathrm{F}_{\omega}^{-1}(\mathrm{n}) \quad$ - функція, обернена до функції $\eta=\mathrm{F}_{\omega}(\mathrm{n})(\omega)$;

$\gamma$ - рівень гарантії.

Як можна бачити з вищевикладеного, отримані значення показника ефективності лінії зв'язку пов'язані 3 винайденням спільного закону розподілу показника іï результатів $\overrightarrow{\mathrm{X}}$ та вимог до них $\overrightarrow{\mathrm{Y}}$, які мають розмірність $\mathrm{n}$. Одним із найбільш коректних шляхів подолання труднощів, які пов'язані з великою розмірністю векторів $\overrightarrow{\mathrm{X}}$ i $\overrightarrow{\mathrm{Y}}$, є застосування методу ведучої компоненти [12], суть якого полягає у виділенні із компонент вектору $\overrightarrow{\mathrm{X}}$ одної або декількох ведучих $\mathrm{i}$ накладення на решту ведених компонент $\vec{X}^{\prime \prime}$ стохастичних обмежень виду $\mathrm{L}=\left(\overrightarrow{\mathrm{X}}_{>}^{<} \overrightarrow{\mathrm{Y}}\right)$.

Отже, для випадку однієї ведучої компоненти $\mathrm{x}$ вираз (4) прийме такий вид

$$
\Phi_{\mathrm{X} / \mathrm{L}}(\widetilde{\mathrm{x}})=\int_{-\infty}^{\infty}(\mathrm{n}-1) \int_{-\infty}^{\infty} \frac{\Phi_{\overrightarrow{\mathrm{X}}_{(\mathrm{n})}}\left(\mathrm{x}, \tilde{\overrightarrow{\mathrm{Y}}}_{(\mathrm{n}-1)}^{\prime \prime}\right)}{\Phi_{\overrightarrow{\mathrm{X}}_{(\mathrm{n})}}\left(\widetilde{\overrightarrow{\mathrm{Y}}}_{(\mathrm{n}-1)}^{\prime \prime}\right)} \mathrm{dF}_{\overrightarrow{\mathrm{Y}}^{\prime \prime}(\mathrm{n}-1)},
$$

де: $\mathrm{L}=\left(\overrightarrow{\mathrm{X}}_{(\mathrm{n}-1)}^{\prime \prime} \geq \overrightarrow{\mathrm{Y}}_{(\mathrm{n}-1)}^{\prime \prime}\right) ; \Phi_{\overrightarrow{\mathrm{X}}_{(\mathrm{n})}}\left(\widetilde{\overrightarrow{\mathrm{Y}}}_{(\mathrm{n}-1)}^{\prime \prime}\right)-$ спільна функція розподілу ведених компонент.

Оцінювання ефективності цифрових ліній зв'язку за ймовірнісно-часовим критерієм

Проаналізуємо застосування розглянутої методики для оцінювання ефективності цифрових радіорелейних та тропосферних ліній (далі - РРЛ та ТРЛ) за ймовірнісно-часовим критерієм. 3 метою наочності розрахунків які проводитимусь припустимо, що всередині кожної із однорідних за фізичним змістом груп компонент векторного показника якості $\vec{X}$ проведена ї попередня функціональна згортка i загальна кількість компонент (груп) скорочено до трьох:

$$
\overrightarrow{\mathrm{X}}=\left\|\mathrm{x}_{1}, \mathrm{x}_{2}, \mathrm{x}_{3}\right\|^{\mathrm{T}},
$$

де $\mathrm{x}_{1}$ - ефект, $\mathrm{x}_{2}$ - час $\mathrm{x}_{3}$ - витрати відповідно. Фізичний зміст компонент може бути наступним: $\mathrm{x}_{1}$ - коефіцієнт надлишковості передаваємої інформації, обернений коефіцієнту використання пропускної спроможності лінії і визначає мий як відношення фактично передаваємого об’єму інформації до корисного $\left(\mathrm{x}_{1}=\frac{\mathrm{V}_{\phi}}{\mathrm{V}_{\mathrm{iн \phi}}}=\theta\right)$;

$\mathrm{x}_{2}$ - поточний час доставки повідомлення відповідної категорії терміновості $\left(\mathrm{x}_{2}=\mathrm{t}_{\mathrm{d}}[\mathrm{c}]\right)$;

$\mathrm{x}_{3}$ - пропускна спроможність лінії зв'язку $\left(x_{3}=c[\sigma i m / c]\right)$.

Відповідно до методики [9-13] визначимо інтегральний закон розподілу вектору:

$$
\begin{aligned}
& \Phi_{\overrightarrow{\mathrm{X}}}\left(\mathrm{x}_{1}, \mathrm{x}_{2}, \mathrm{x}_{3}\right)=\mathrm{P}\left[\left(\mathrm{x}_{1} \leq \widetilde{\mathrm{x}}_{1}\right) \cap\left(\mathrm{x}_{2} \leq \widetilde{\mathrm{x}}_{2}\right) \cap\left(\mathrm{x}_{3} \leq \widetilde{\mathrm{x}}_{3}\right)\right]= \\
& =\int_{\mathrm{x}_{1}}^{\infty} \int_{-\infty}^{\mathrm{x}_{2}} \int_{-\infty}^{\mathrm{x}_{3}} \varphi_{\overrightarrow{\mathrm{X}}}\left(\mathrm{x}_{1}^{\prime}, \mathrm{x}_{2}^{\prime}, \mathrm{x}_{3}^{\prime}\right) \mathrm{d \textrm {x } _ { 1 } ^ { \prime }} \mathrm{dx}_{2}^{\prime} \mathrm{dx}_{3}^{\prime}
\end{aligned}
$$

Нехай пропускна спроможність РРЛ (ТРЛ) змінюється в межах від $\mathrm{a}$ до $\mathrm{b}$ деяким випадковим чином, наприклад у відповідності до рівномірного закону розподілу:

$$
\varphi_{\mathrm{X}_{3}}=\frac{\prod\left(\mathrm{x}_{3} ; \mathrm{a}, \mathrm{b}\right)}{\mathrm{b}-\mathrm{a}}
$$

де: $\prod\left(\mathrm{x}_{3} ; \mathrm{a}, \mathrm{b}\right)$ - селектор інтервалу, який приймає значення 1 при $\mathrm{a} \leq \mathrm{x} \leq \mathrm{b}$ та 0 в іншому випадку.

Допустимо, що поточний час доставки повідомлення $\mathrm{x}_{2}$ складається із двох незалежних доданків

$$
\mathrm{x}_{2}=\mathrm{x}_{\mathrm{r}}+\mathrm{x}_{\mathrm{f}},
$$

де розрахунковий час доставки повідомлення, визначається затратами $\mathrm{x}_{3}=\mathrm{c}$,

$$
\mathrm{x}_{\mathrm{r}}=\alpha / \mathrm{x}_{3},
$$

де: $\alpha=\mathrm{V}_{\mathrm{f}}-$ коефіцієнт пропорційності, який рівний фактично передаваємому об'єму інформації;

$\mathrm{x}_{\mathrm{f}}$ - випадкова складова часу доставки повідомлення, яка визначає відхилення $\mathrm{t}_{\mathrm{d}}$ від $\mathrm{x}_{\mathrm{r}}$.

Далі будемо вважати, що $\mathrm{x}_{\mathrm{f}}-$ ненегативна випадкова величина, яка розподілена за показовим законом 3 параметром $\mu$, тоді умовне розподілення поточного часу доставки

$$
\varphi_{\mathrm{x}_{2} / \mathrm{x}_{3}}=\mu \exp \left(-\mu\left(\mathrm{x}_{2}-\frac{\alpha}{\mathrm{x}_{3}}\right) \Delta\left(\mathrm{x}_{2}-\frac{\alpha}{\mathrm{x}_{3}}\right)\right),
$$

де: $\Delta(\mathrm{x}-\alpha)-$ селектор променя, який приймає значення 1 при $\mathrm{x} \geq \alpha$ та 0 в решті випадків;

$\mu$ - параметр розподілу.

Нарешті, оскільки коефіцієнт надмірності прямопропорційний пропускної спроможності та часу доставки повідомлення: 


$$
\mathrm{x}_{1}=\mathrm{V}_{\phi} / \mathrm{V}_{\mathrm{iн \phi}} \cdot
$$

то умовне розподілення значень коефіцієнта буде визначатися виразом

$$
\varphi_{\mathrm{x}_{1} / \mathrm{x}_{3} \mathrm{x}_{2}}=\sigma\left(\mathrm{x}_{1}-\beta \mathrm{x}_{3} \mathrm{x}_{2}\right),
$$

де $\sigma(\mathrm{x}-\mathrm{a})=\left\{\begin{array}{c}\infty п р и \mathrm{x}=\mathrm{a} \\ 0 п р и \mathrm{x} \neq \mathrm{a}\end{array}-\right.$ дельта-функція Дірака.

3 урахуванням виразів (13), (16) та (18) щільність розподілу вектору $\overrightarrow{\mathrm{X}}$ буде мати вигляд

$$
\begin{aligned}
& \varphi_{\overrightarrow{\mathrm{X}}}\left(\mathrm{x}_{1}, \mathrm{x}_{2}, \mathrm{x}_{3}\right)=\varphi_{\mathrm{x}_{3}} \varphi_{\mathrm{x}_{2} / \mathrm{x}_{3}} \varphi_{\mathrm{x}_{1} / \mathrm{x}_{2} \mathrm{x}_{3}}= \\
& =\frac{\prod\left(\mathrm{x}_{3} ; \mathrm{a}, \mathrm{b}\right)}{\mathrm{b}-\mathrm{a}} \mu \exp -\mu\left(\mathrm{x}_{2}-\frac{\alpha}{\mathrm{x}_{3}}\right) \Delta\left(\mathrm{x}_{2}-\frac{\alpha}{\mathrm{x}_{3}}\right) \times, \\
& \times \sigma\left(\mathrm{x}_{1}-\beta \mathrm{x}_{3} \mathrm{x}_{2}\right)
\end{aligned}
$$

Відповідно до (5) функція розподілу випадкового вектору вимог при умові їх незалежності

$$
\mathrm{F}_{\overrightarrow{\mathrm{Y}}}=\mathrm{F}_{\mathrm{y}_{3}^{\text {потр }}} \mathrm{F}_{\mathrm{y}_{2}^{\text {потр }}} \mathrm{F}_{\mathrm{y}_{1}^{\text {потр }}}
$$

де: $y_{i}^{\text {потр }}$ - вимоги до відповідних показників якості $\mathrm{x}_{\mathrm{i}}$.

При виділенні в якості ведучої компоненти часу доставки $\mathrm{x}_{2}$ умовна функція розподілу $\Phi_{\mathrm{x}_{2} / \mathrm{L}} \quad 3$ урахуванням (19) та умові детермінованості вимог на ресурс $\mathrm{y}_{3}=\mathrm{c}$ (при чому $(\mathrm{a} \leq \mathrm{c} \leq \mathrm{b}))$ та ефект $\mathrm{y}_{1}=\mathrm{e} \phi \leq \alpha \beta$, а також нормальному розподілу вимог до часу доставки $\mathrm{F}_{\mathrm{y}_{2}}=\mathrm{F}_{\sigma}\left(\frac{\mathrm{y}_{2}-\overline{\mathrm{T}}_{Д}}{\sigma_{\mathrm{T}_{д}}}\right)$ буде мати вигляд

$$
\Phi_{\mathrm{x}_{2} / \mathrm{L}}=\prod\left(\mathrm{x}_{2} ; \frac{\alpha}{\mathrm{c}} ; \frac{\alpha}{\mathrm{a}}\right)\left\{\mathrm{A}\left(\mathrm{x}_{2}\right)-\mathrm{B}\left(\mathrm{x}_{2}\right) \exp ^{-\mu \mathrm{x}_{3}}\right\} \text {, }
$$

де: $\mathrm{A}\left(\mathrm{x}_{2}\right)=\frac{\mathrm{cx}_{2}-\alpha}{\mathrm{x}_{2}(\mathrm{c}-\mathrm{a})}$;

$$
\begin{array}{r}
\mathrm{B}\left(\mathrm{x}_{2}\right)=\frac{\alpha \mu}{\mathrm{c}-\mathrm{a}}\left[\mathrm{G}\left(\mu \mathrm{x}_{2}\right)-\mathrm{G}\left(\frac{\mu \alpha}{\mathrm{c}}\right)\right], \\
\mathrm{G}_{\mathrm{y}}=\mathrm{M}[\mathrm{i}(\mathrm{y})]-\exp ^{\mathrm{y}} / \mathrm{y}, \text { a } \mathrm{M}[\mathrm{i}(\mathrm{y})]-\text { інтегральна }
\end{array}
$$
показова функція.

Нарешті, з урахуванням (6), (7) та (8) у випадку мінімальних затрат $(\mathrm{c}=\mathrm{a})$ показники ефективності РРЛ (ТРЛ) визначаються наступними залежностями

\section{Jimepamypa}

1. Digital Radio-Relay Systems. - Geneva: ITU. - 1996. Слипченко В.И. Войны шестого поколения. Оружие и военное искусство будущего. Москва. 2002. 384 с. 2. Матеріали науково-практичного семінару. Перспективи розвитку телекомунікаційних та інформаційних систем військового призначення за досвідом участі ЗС України в АТО. Київ: НУОУ імені

$$
\begin{aligned}
& \mathrm{P}_{\mathrm{B}}=\bar{\omega}=\int_{0}^{1}\left[1-\mathrm{F}_{\omega}(\mathrm{n})(\omega)\right] \mathrm{d} \omega=1-\mathrm{F}\left(\frac{\alpha-\mathrm{a} \overline{\mathrm{T}}_{\text {Д }}}{\left.\mathrm{a} \sigma_{\mathrm{T}_{\text {Д }}}\right)-}\right. \\
& -\exp \left(\frac{\left.\alpha \mu-\alpha \mu \overline{\mathrm{T}}_{\text {Д }}-\frac{\mu^{2} \sigma^{2} \overline{\mathrm{T}}_{\text {Д }}}{2}\right)}{\mathrm{a}}\left[1-\mathrm{F}_{\sigma}\left(\frac{\alpha-\alpha \overline{\mathrm{T}}_{\text {Д }}}{\alpha \sigma_{\overline{\mathrm{T}}}}+\mu \sigma_{\overline{\mathrm{T}}_{\text {Д }}}\right)\right]\right.
\end{aligned}
$$

Ta

$$
\begin{aligned}
& \omega^{\Gamma}(\gamma)=\mathrm{F}_{\omega_{2}}^{-1}(1-\gamma)=\Delta\left[1-\mathrm{F}_{\sigma}\left(\frac{\alpha-\alpha \overline{\mathrm{T}}_{д}}{\alpha \sigma_{\overline{\mathrm{T}}}}-\gamma\right)\right] \times \\
& \times[1-\exp ],
\end{aligned}
$$

де $\mathrm{F}_{\sigma}(\mathrm{u})=\frac{1}{\sqrt{2 \pi}} \int_{-\infty}^{\mathrm{u}} \mathrm{e}^{-\mathrm{v}^{2} / 2} \mathrm{dV}-$ інтеграл імовірності.

\section{Висновки й перспективи подальших досліджень}

Отже, ефективність РРЛ (ТРЛ) збільшується із зменшенням затрат пропускної спроможності лінії на обслуговування (сервіс) передаваємої корисної інформації, тобто із зменшенням коефіцієнта надмірності $\theta$.

Сервісні витрати пропускної спроможності лінії визначаються: необхідністю передачі (прийому) синхросигналів та адреси повідомлення, а також необхідністю забезпечення потрібної завадозахищеності передаваємої інформації та/або величиною девіації частоти (або індексом частотної модуляції), полосою фільтрування та необхідністю забезпечення електромагнітної сумісності радіоелектронних засобів.

Таким чином, для підвищення ефективності функціонування РРЛ (ТРЛ) необхідно розробляти методи формування, обробки та демодуляції радіосигналів, а також системи телеуправління та телесигналізації із мінімально необхідної інформаційною надлишковістю при мінімальних затратах просторових, частотних та часових ресурсів.

В перспективі планується здійснити оцінювання ефективність функціонування ліній зв’язку та обгрунтувати рекомендації щодо підвищення ефективності їх функціонування. 
К., 1998. - 190 с. 5. Дружинин С. В. Методика оценки эффективности функционирования системы связи армейского корпуса в операции объединенных сил бистрого реагирования: дисс. ... канд. воен. наук: 20.02.12 / Дружинин Светозар Витальевич. Полтава. 2005. 197 c. 6. Корецький А. А. Обгрунтування пропозицій щодо підвищення ефективності функціонування первинної мережі зв'язку оперативного командування в оборонній операції: дис. ... канд. військ. наук: 20.01.01. / Корецький Андрій Анатолійович. Київ. 2003. 161 с. 7. Корнієнко І.В. Методика побудови просторової структури транкінгової системи зв'язку 3 ексцентричним розташуванням базових станцій в умовах радіоелектронного впливу противника: дис. $\ldots$ канд. техн. наук: 20.02.12 / Корнієнко Ігор Валентинович. Київ. 2005. 267 с. 8. Роговенко С. Б. Розробка рекомендацій щодо підвищення ефективності функціонування системи управління армійського корпусу під час підготовки оборонної операції початкового періоду війни: дис. ... канд.. військ. наук: 20.01.03 Роговенко Сергій Борисович. Київ. НАОУ. 1997. 194 с. 9. Огороднійчук М. Д. Чайка Ю. Д., Оксіюк О. Г. Комплекси i засоби військових телекомунікаційних мереж. Київ: НУОУ, 2010. 384 с. 10. Розум І. Ю., Савісько П. А., Огороднійчук М. Д. Застосування телекомунікаційних систем у процесі управління військами: посіб. для вищ. військ. навч. закл. Київ: НУОУ. 2016. 164 с. 11. Методики по расчету и оценке полевых систем связи. Ленинград: ВАС. 1985. 80 с. 12. Терентьев В. М. Критерии оптимальности цифровых сетей и линий связи. Краткий курс лекций. Ленинград: ВАС. 1981. 44 с. 13. Петухов Г.Б. Теоретические основы и методы исследования эффективности оперативных целенаправленных процессов. Уч. пособие. МО СССР. 1979. 176 с. 14. Зв'язок військовий. Терміни та визначення. ДСТУ В3265-95. Київ: Держстандарт України. 1996. 23 с. 15. Радіозв'язок радіорелейний. Терміни та визначення. ДСТУ 3610-97. Київ: Держстандарт України. 1998. 10 с.

\title{
МЕТОДИКА ОЦЕНИВАНИЯ ЭФФЕКТИВНОСТИ ФУНКЦИОНИРОВАНИЯ ЛИНИИ СВЯЗИ
}

\author{
Шевченко Дмитрий Георгиевич (кандидат военных наук)
}

Национальный университет обороны Украины имени Ивана Черняховского, Киев, Украина

В статье рассмотрен актуальный вопрос усовершенствования научно-методического аппарата оценивания эффективности функционирования линий связи. Проанализировань последних исследования и публикации по этому вопросу. Проведенный анализ свидетельствует о том, что эти методики не обеспечивают достаточньй уровень точности и объективности оценки в связи с тем, что не учтен опыт применения цифровых линий связи в операциях и некоторых других факторов, которые существенно влияют на эффективность их функционирования в этих условиях.

В статье рассматривается методический подход для решения прикладной задачи, который основан на применении метода векторной оценки показателя эффективности. Предлагается интегральный показатель эффективности функционирования ичифровой линии связи для решения поставленной задачи. Приведены соотношения для оченивания внешних и внутренних факторов и их влияние на функционирование линии связи.

Предложенная методика дает возможность получить более объективную и адекватную оценку. Применение данного метода векторной оценки эффективности лишает необходимости решения проблемного вопроса, который заключается в нормировании компонент критерия оценки, приведения к единой размерности та масштаба, по ранжированию или назначении весовых коэффициентов, а также свертки отдельных компонентов, что позволяет применять описанньй в статье метод для задач оценивания эффективности цифровых линий и сетей связи.

Ключевые слова: система связи, ијифровые линии связи, эффективность, качество.

\section{COMMUNICATION LINE PERFORMANCE EVALUATION METHODOLOGY}

\author{
Dmytro Shevchenko (Candidate of Military Sciences)
}

\section{National Defense University of Ukraine named by Ivan Cherniakhovsky, Kyiv, Ukraine}

The article deals with the actual issue of improving the scientific and methodical apparatus for evaluating the effectiveness of the digital communication line. Recent researches and publications on this issue have been analyzed. The analysis shows that these methods can not provide a sufficient level of accuracy and objectivity of the assessment due to the failure to take into account the experience of using communication lines during the operation and some factors that significantly influence the efficiency of digital lines functioning in these conditions.

Another methodological approach for solving the applied problem is considered in the article. The application of the method of vector estimation of the efficiency indicator is proposed. The determined integral 
indicator of efficiency and the criterion for evaluating the effectiveness of the digital line for solving the problem. The relationships for estimating external and internal factors and their influence on the efficiency of digital communication line operation are presented.

The proposed method gives an opportunity to obtain a more objective and adequate assessment of the efficiency of the communication line. The application of this method of vector estimation of efficiency eliminates the need to solve a problematic issue, which consists in the normalization of the components of the evaluation criterion, bringing to uniform dimensions and scales, their ranking or assigning weight coefficients, and also convolutions of individual components, which makes it possible to use the method described in the article for problems evaluation of the efficiency of different kind of lines and communication networks.

Key words: communication system, digital communication line, efficiency, quality.

\section{References}

1. Digital Radio-Relay Systems. - Geneva: ITU. - 1996. Slipchenko VI Voynyi shestogo pokoleniya. Oruzhie i voennoe iskusstvo buduschego. Moskva. 2002. 384 s. 2. MaterIali naukovo-praktichnogo semInaru. Perspektivi rozvitku telekomunlkatsIynih ta InformatsIynih sistem vlyskovogo priznachennya za dosvIdom uchastI ZS UkraYini v ATO. KiYiv: NUOU ImenI Ivana Chernyahovskogo. 2014. 38 s. 3. MaterIali naukovopraktichnogo semInaru. OsoblivostI organIzatsIYi radIozv'yazku v ATO. KiYiv: NUOU ImenI Ivana Chernyahovskogo. 2015. 22 s. 4. Dovbnya S. Ya. PIdvischennya mozhlivostey sistemi zv'yazku armIyskogo korpusu $\mathrm{v}$ oboronnIy operatsIYi pochatkovogo perIodu vIyni: dis. ... kand. vlysk. nauk: 20.01.03 / Dovbnya SergIy Yakovich. - K., 1998. - 190 s 5. Druzhinin S. V. Metodika otsenki effektivnosti funktsionirovaniya sistemyi svyazi armeyskogo korpusa $\mathrm{v}$ operatsii ob'edinennyih sil bistrogo reagirovaniya: diss. ... kand. voen. nauk: 20.02.12/ Druzhinin Svetozar Vitalevich. Poltava. 2005. 197 s. 6. Koretskiy A. A. ObGruntuvannya propozitsly schodo pIdvischennya efektivnostI funktsIonuvannya pervinnoYi merezhI zv'yazku operativnogo komanduvannya v oboronnIy operatsIYi: dis. ... kand.. vlysk. nauk: 20.01.01./ Koretskiy Andrly Anatollyovich. KiYiv. 2003. 161 s. 7. KornIEnko I.V. Metodika pobudovi prostorovoYi strukturi trankIngovoYi sistemi zv'yazku z ekstsentrichnim roztashuvannyam bazovih stantsIy $\mathrm{v}$ umovah radIoelektronnogo vplivu protivnika: dis. ... kand. tehn. nauk: 20.02.12 / KornIEnko Igor Valentinovich. KiYiv. 2005. 267 s. 8. Rogovenko S. B. Rozrobka rekomendatsly schodo pIdvischennya efektivnostI funktsIonuvannya sistemi upravlInnya armlyskogo korpusu pId chas pIdgotovki oboronnoYi operatsIYi pochatkovogo perIodu vlyni: dis. ... kand. vlysk. nauk: 20.01.03 Rogovenko Sergly Borisovich. KiYiv. NAOU. 1997. 194 s. 9. Ogorodniychuk M. D. Chayka Yu. D., OksIyuk O. G. Kompleksi I zasobi vIyskovih telekomunIkatsIynih merezh. KiYiv: NUOU, 2010. 384 s. 10. Rozum I. Yu., Savisko P. A., OgorodnIychuk M. D. Zastosuvannya telekomunIkatsIynih sistem u protsesI upravlInnya vIyskami: posIb. dlya visch. vIysk. navch. zakl. KiYiv: NUOU. 2016. 164 s. 11. Metodiki po raschetu i otsenke polevyih sistem svyazi. Leningrad: VAS. 1985. 80 s. 12. Terentev V. M. Kriterii optimalnosti tsifrovyih setey i liniy svyazi. Kratkiy kurs lektsiy. Leningrad: VAS. 1981. 44 s. 13. Petuhov G.B. Teoreticheskie osnovyi i metodyi issledovaniya effektivnosti operativnyih tselenapravlennyih protsessov. Uch. posobie. MO SSSR. 1979. 176 s. 14. Zv'yazok vIyskoviy. TermIni ta viznachennya. DSTU V-3265-95. KiYiv: Derzhstandart UkraYini. 1996. 23 s. 15. RadIozv'yazok radIoreleyniy. TermIni ta viznachennya. DSTU 3610-97. KiYiv: Derzhstandart UkraYini. 1998. 10 s. 